\title{
Lead Ammunition and Illegal Poisoning: Further International Agreements Are Needed to Preserve Vultures and the Crucial Sanitary Service They Provide
}

\author{
Antoni Margalida, ${ }^{\dagger} *$ Raphaël Arlettaz, ${ }^{\dagger}$ and José A. Donázar ${ }^{\ddagger}$ \\ ${ }^{\dagger}$ Division of Conservation Biology, Institute of Ecology and Evolution, University of Bern, Baltzerstrasse 6, 3012 Bern, Switzerland \\ ${ }^{*}$ Department of Conservation Biology, Estación Biológica de Doñana, CSIC, Avenida Américo Vespucio s/n, Isla de la Cartuja, 41092 \\ Sevilla, Spain
}

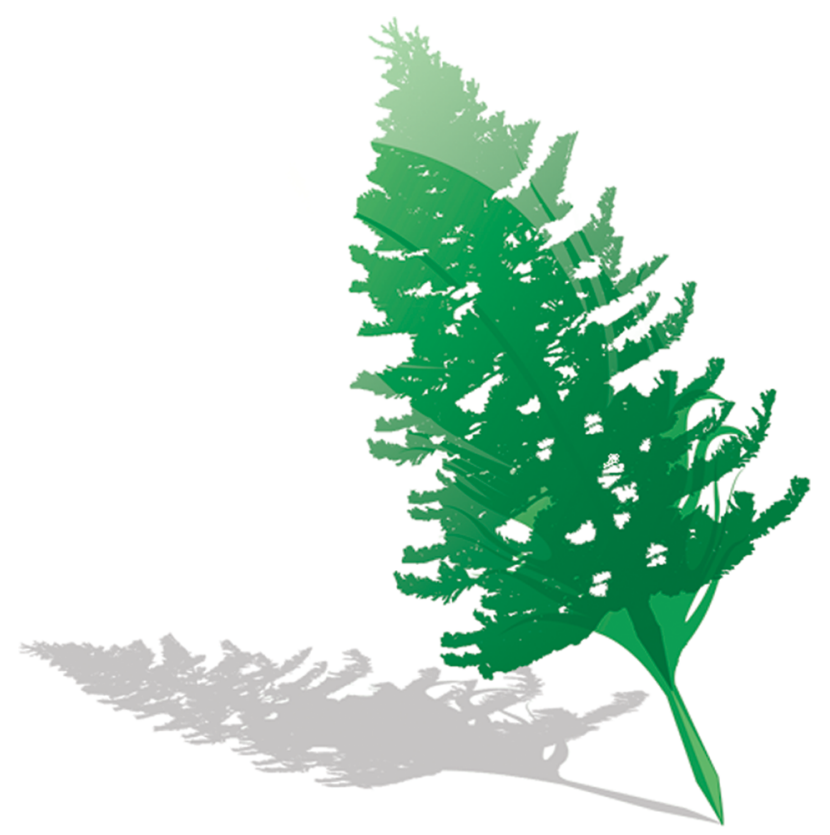

W hen feeding on wild game carcasses, free-ranging scavengers, such as vultures, risk ingestion of illegal poison baits intended to kill predators or lead particles stemming from ammunition used for hunting. These two threats are currently massively affecting the populations of European, African, and American scavengers. ${ }^{1,2}$ The game meat trade furthermore commercializes thousands of tonnes of meat contaminated with lead, which adds a serious public health dimension to the issue. ${ }^{2}$ Scientific evidence supports the view that the quasi-extinction of vertebrate mesofaunal elements, such as the California condor Gymnogyps californianus in America or the Bearded vulture Gypaetus barbatus in Europe, has been largely caused by poisoning. This calls for a rapid mitigation of the effects of toxicosis on wildlife, either intentional or unintentional. In Spain only, a country home to over $95 \%$ of all European avian scavengers, more than 4000 vultures were illegally poisoned during the last two decades. ${ }^{1}$

The millenary relationship between vultures and humans, initially founded on the crucial ecosystem service provided free of charge by the birds, is considered as a model of humanwildlife coexistence, which has traditionally facilitated the preservation of these amazing animals. By removing carrion and carcasses, vultures contribute to the elimination of risks of disease transmission; this sanitation service entails a series of health, economic, and cultural benefits for human beings. More recently, vultures have become a major asset in the ecotourism industry. However, large-scale threats are currently decimating populations of avian scavengers worldwide. International cooperation has proven essential to reverse this negative trend, as revealed by recent action in Asia and Europe. ${ }^{3,4}$ In the Indian subcontinent, the abrupt and widespread decline of vulture populations, as a consequence of ingestion of diclofenac by domestic ungulates, has led to the ban of this veterinary drug, which necessitated a rapid, and unprecedented international political agreement between the governments of India, Pakistan, Nepal, and Bangladesh. Since the implementation of this measure, the populations of Asian vultures have shown first signs of recovery. ${ }^{3}$ In Europe, restrictive health regulations promulgated in the wake of the outbreak of bovine spongiform encephalopathy in 2001, provoked a massive reduction in the availability of livestock carcasses, suppressing vulture main food source and threatening their populations. ${ }^{4}$ Here, as in Asia, a consensus had to be built among scientists, conservationists, and managers toward edicting novel, more flexible European Union regulations, enforced in 2011, eventually reconciling sanitary and environmental policies. ${ }^{5}$

These stories show how cooperation between scientists and politicians are essential to biodiversity conservation and the maintenance of crucial ecosystem functions and services. Although these few examples are encouraging, there is still a long way to go until New and Old-world vulture conservation is secured. Such political actions also request a high level of commitment of scientists. In these two cases, a strong argumentation constructed upon scientific evidence was decisive for reaching a broad consensus for mitigating the impact of non-natural mortality factors decimating scavenger populations. The consequence of inaction would be unaffordable: the disappearance of apex scavengers, and related ecosystem services, over wide regions, would necessitate costly reintroduction projects to restore populations, not to mention human health issues that might emerge following the decline of natural scavenging services. In order to exit such a dark scenario, new international agreements are urgently needed, which should involve collaborations between scientists, conservationists, farmers, hunters, and legislators. The recent 
successful Asian and European restoration actions around vultures pave the road for such novel initiatives.

\section{AUTHOR INFORMATION}

\section{Corresponding Author}

*E-mail: antoni.margalida@iee.unibe.ch.

Notes

The authors declare no competing financial interest.

\section{REFERENCES}

(1) Margalida, A. Baits, budget cuts: A deadly mix. Science 2012, 338, 192.

(2) Lambertucci, S. A.; Donázar, J. A.; Hiraldo, F. Poisoning people and wildlife with lead ammunition: time to stop. Environ. Sci. Technol. 2010, 44, 7759.

(3) Balmford, A. Pollution, politics, and vultures. Science 2013, 339, 653.

(4) Donázar, J. A.; Margalida, A.; Carrete, M.; Sánchez-Zapata, J. A. Too sanitary for vultures. Science 2009, 326, 664.

(5) Margalida, A.; Carrete, M.; Sánchez-Zapata, J. A.; Donázar, J. A. Good news for European vultures. Science 2012, 335, 284. 